\title{
Combustion Characteristics of CAI Combustion with Alcohol Fuels
}

\author{
Manida Tongroon and Hua Zhao \\ Centre for Advanced Powertrain and Fuels Research, Brunel University, UK
}

\begin{abstract}
Due to its potential for simultaneous improvement in fuel consumption and exhaust emissions, controlled autoignition (CAI) combustion has been subject to continuous research in the last several years. At the same time, there has been a lot of interest in the use of alternative fuels in order to reduce reliance on conventional fossil fuels. Therefore, this experimental study has been carried out to investigate the effect of alcohol fuels on the CAI combustion process and on the resulting engine performance.
\end{abstract}

The experimental work was conducted on an optical single cylinder engine with an air-assisted injector. To achieve controlled autoignition, residual gas was trapped in the cylinder by using negative valve overlap and an intake air heater was used to ensure stable CAI combustion in the optical engine. Methanol, ethanol and blended fuels were tested and compared with the results of gasoline. The combustion processes were analysed through total chemiluminescence images captured with a high speed camera equipped with an intensifier. In addition, the effect of spark discharge was investigated.

The images show that CAI combustion of alcohol fuels was characterized with fast and early autoignition combustion compared with pure gasoline. Chemiluminescence of the gasoline fuel was most visible and it decreased with increasing percentage of oxygenated fuels. During the re-compression stroke, chemiluminescence images of the gasoline engine indicated the presence of oxidation reactions. In the presence of spark discharge, the location of charge ignition was dominated by spark discharge at the center of cylinder while simultaneous autoignition sites were found around the periphery of the combustion chamber for nonspark-assisted ignition.

\section{INTRODUCTION}

In order to help alleviate oil depletion and air pollution issues, controlled autoignition combustion has been developed over the last three decades. The fundamental principle of CAI is to combine the characteristics of homogeneous charge mixture of SI engines together with spontaneous autoignition of CI engines. To attain CAI combustion, sufficiently high temperature for self-ignition of charge mixture to occur is a key factor. Therefore, many approaches, including heating of the intake charge, increasing compression ratio and utilizing hot residual gas or EGR have been employed [1]. In particular, hot residual gas trapped by means of negative valve overlap has been widely adopted by many researchers. However, developments to the process have continued in order to address the major drawbacks of CAI - the limited operating range and relatively high HC emission. Therefore, as a method of extending the operating regime, many investigations, including the current study, apply spark-assisted combustion and in-cylinder fuel injection strategies to control combustion phasing [2-5].

In addition to the above methods, fuels of lower autoignition temperature, for example n-heptanes, DME, or blended fuels, have been employed to attain CAI combustion. Sustainable renewable fuels such as methanol and ethanol, besides aiding the implementation of CAI combustion, is an alternative way to help reduce energy depletion or even substitute crude oil based fuels. Cleaner combustion and so reduced exhaust emissions is Page 1 of 19 
another benefit of these oxygenated fuels. Thus, it is interesting to combine the advantage of CAI combustion with oxygenated fuels. In the previous study, Christensn et al [6] compared ethanol with gasoline in a high compression ratio HCCI engine and demonstrated the high load limit that could be achieved with ethanol. Oakely et al [7] have shown that methanol and ethanol could be operated in CAI combustion mode over a wider range of relative air/fuel ratios and EGR concentrations than gasoline in a single cylinder engine with elevated intake charge temperature. Iida [8] conducted experimental studies of CAI combustion in a two-stroke ATAC engine and found that methanol provided larger range of CAI combustion than gasoline. Studies by Xie et al [9] and $\mathrm{Li}$ et al [10] showed that alcohol fuels tended to autoignite earlier and produced less emissions. However, most of these studies focused on the attainability of CAI combustion and the operating range limits when alcohol fuels were used, while there are few studies providing an insight into the combustion process when using these alcohol fuels.

Optical techniques are powerful tools to investigate in-cylinder combustion phenomena for both conventional and CAI combustion engines. With varying levels of complexity of both equipment and technique, they have been applied extensively by many researchers in SI and CI engines for a long period of time [11, 12]. For CAI, many researchers have successfully applied PLIF techniques to capture fluorescence of $\mathrm{OH}$ and formaldehyde to analyse the autoignition and combustion process [13-15]. Application of simpler techniques which do not rely on laser illumination and doped fuels for imaging combustion can allow for more realistic engine conditions. Chemiluminescence emission is the result of naturally occurring chemical reactions, due to the decaying energy of radical chemical species from the excited to the ground state. Total chemiluminescence was captured by Persson et al [16] to elucidate early flame development with the influence of spark discharge. He found that using spark assistance had a potential to extend the operating regime of HCCI combustion. Dec et al [17] indicated the thermal stratification with the late emission of light on the piston crown and cylinder head in CAI engines. Also, Aleiferis et al [18] found the effects of inlet air heating, internal EGR and spark discharge to initiate combustion and flame structure through total emission imaging. Moreover, due to the specific chemiluminescence wavelengths from each molecule, it can be used to identify the presence of certain species and therefore the occurrence of the reactions concerned. Hence, chemiluminescence imaging of $\mathrm{OH}, \mathrm{CHO}$ and $\mathrm{CH}$ radicals had been previously employed to indicate defined combustion process occurring as shown by Hultqvist et al [19] and Yang et al [20].

In the current study, optical diagnostics based on natural chemiluminescence have been applied to investigate the combustion characteristics, flame structure and in-cylinder process of CAI combustion when using alcohol fuels and their blends with gasoline. In particular, the fuel reforming reactions following the fuel injection during the negative valve overlap period were investigated. Engine experiments were conducted with the blended fuels as well as gasoline, as a baseline reference. Chemiluminescence imaging was recorded and analysed on three selected fuels. In addition, the influence of spark discharge to control CAI combustion phasing was investigated.

\section{EXPERIMENT SETUP}

\section{ENGINE}

An optically accessible single cylinder engine with a transparent piston window was used throughout for chemiluminescence imaging while the same engine, but fitted with a metal piston was employed for thermodynamic engine tests. With the optical piston, images were obtained of the combustion chamber through a $55 \mathrm{~mm}$ piston quartz window by means of a $45^{\circ}$ mirror as shown in Figure 1 . To achieve CAI combustion, charge mixture temperatures were increased through residual gas trapping by negative valve overlap in

Page 2 of 19 
conjunction with an intake air heater. An air-assisted injector with individual adjustable air and fuel quantities and timing was fitted in the center of the cylinder head provided by Orbital Engine Corporation Ltd. Detailed specifications of the engine are shown in Table 1 and previous papers [2, 20].

Before testing, engine coolant and oil were warmed up to $100{ }^{\circ} \mathrm{C}$ and $50{ }^{\circ} \mathrm{C}$ respectively. Intake air was heated up to $175{ }^{\circ} \mathrm{C}$ by a $3 \mathrm{KW}$ air heater installed in the intake pipe. An engine speed of 1600 rpm was used throughout the experiments. Fuel was injected directly into the combustion chamber during the negative valve overlap period after exhaust valves closed, as illustrated in Figure 2.

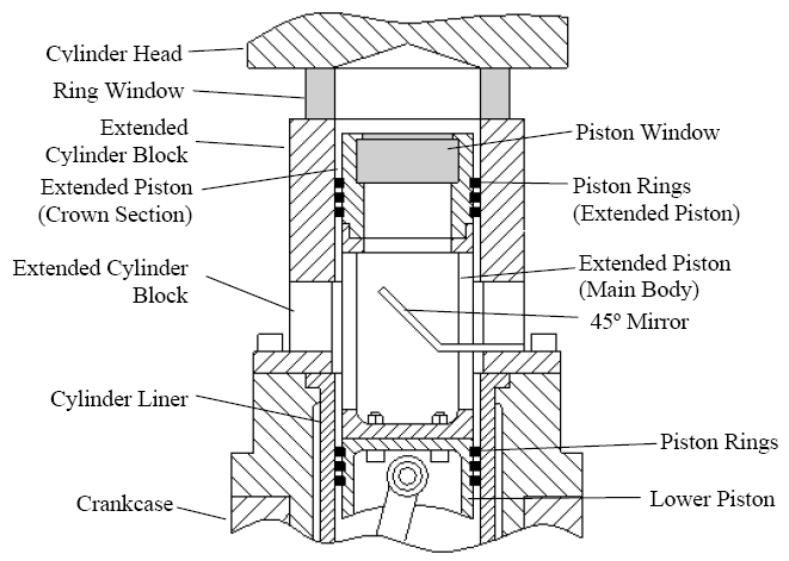

Figure 1. An accessible optical engine

Table1. Engine Specification

\begin{tabular}{|c|c|}
\hline Bore(Extended Piston) & $80 \mathrm{~mm}$. \\
\hline Stroke & $89 \mathrm{~mm}$. \\
\hline Compression Ratio & $9: 1$ \\
\hline Swept Volume & $450 \mathrm{cc}$. \\
\hline Intake Valve Opening & 90 ATDC \\
\hline Exhaust Valve Closing & 80 BTDC \\
\hline Injection Timimg & 80 BTDC \\
\hline
\end{tabular}

Page 3 of 19 


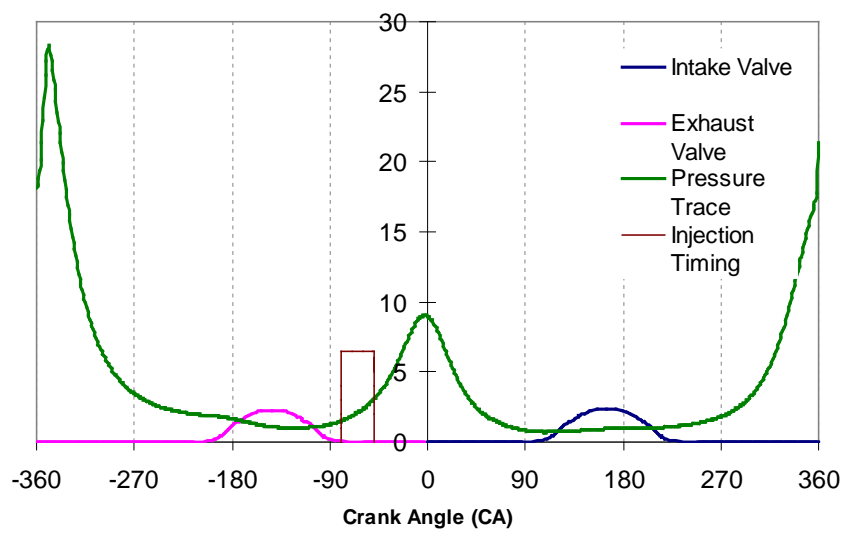

Figure 2. Intake, Exhaust valves and Fuel Injection Timing.

\section{FUELS}

Nine fuels including gasoline, E20, E50, E85, E100, M20, M50, M85 and M100 were employed for the thermodynamic engine experiments, where $\mathrm{E}$ stands for ethanol and $\mathrm{M}$ stands for methanol and the numeric value refers to the percentage by volume mixed with gasoline. Only three pure fuels, gasoline, ethanol and methanol were used for chemiluminescence imaging. The significant properties of fuels are shown in Table 2.

Table 2. Fuels Properties

\begin{tabular}{|c|c|c|c|}
\hline & Gasoline & Ethanol & Methanol \\
& $\left(\mathrm{C}_{n} \mathrm{H}_{1.87 \mathrm{n}}\right)$ & $\left(\mathrm{C}_{2} \mathrm{H}_{5} \mathrm{OH}\right)$ & 6.47 \\
\hline Stoichiometric A/F ratio & 14.6 & 9.00 & 791 \\
\hline Density $\left(\mathrm{kg} / \mathrm{m}^{3}\right)$ & $720-780$ & 789 & $106 / 92$ \\
\hline RON/MON & $95 / 85$ & $107 / 89$ & 1103 \\
\hline Heat of vaporization $(\mathrm{kJ} / \mathrm{kg})$ & 305 & 840 & 385 \\
\hline Lower heating value $(\mathrm{MJ} / \mathrm{kg})$ & 44 & 362 & 1870 \\
\hline Auto-ignition Temperature $\left({ }^{\circ} \mathrm{C}\right)$ & $260-460$ & 1920 & 31.9 \\
\hline Flame Temperature $\left({ }^{\circ} \mathrm{C}\right)$ & 2030 & 16.0 & 11 \\
\hline Vapour Pressure @38 ${ }^{\circ} \mathrm{C}(\mathrm{kPa})$ & $48-108$ & 13 & 0.43 \\
\hline Flash Point $\left({ }^{\circ} \mathrm{C}\right)$ & -43 to -39 & 0.41 & \\
\hline Stoich. Flame speed $(\mathrm{m} / \mathrm{s})$ & 0.34 & & \\
\hline
\end{tabular}

Page 4 of 19 
Throughout each experiment, the relative air/fuel ratio of the charge mixture was kept to stoichiometric value ( $\lambda$ $=1$ ) measured by an AFR analyzer MEXA-110 $\lambda$. Quantity of air for air-assisted injector was kept constantly at $10.8 \mathrm{mg} / \mathrm{cycle}$. The quantify of fuel injected was therefore adjusted with $7.03 \mathrm{mg} / \mathrm{cycle}$ gasoline, $8.20 \mathrm{mg} / \mathrm{cycle}$ ethanol, and $9.44 \mathrm{mg} /$ cycle methanol, by varying the injection pulse width as shown in Table 3.

\section{Table 3 Injection Duration of each fuel.}

\begin{tabular}{|l|c|}
\hline \multicolumn{1}{|c|}{ Fuel } & Injection Duration $\left(10^{-3} \mathrm{~s}\right)$ \\
\hline Gasoline & 3.2 \\
\hline E20 & 3.3 \\
\hline M20 & 3.3 \\
\hline E50 & 3.4 \\
\hline M50 & 3.5 \\
\hline E85 & 3.5 \\
\hline M85 & 3.9 \\
\hline Ethanol & 3.8 \\
\hline Methanol & 4.5 \\
\hline
\end{tabular}

\section{IN-CYLINDER PRESSURE AQUSITION SYSTEM}

A Kistler type 6055 piezo electric pressure transducer, connected to a charge amplifier Kistler type 501, was used to measure the in-cylinder pressure. This pressure transducer is fitted in the cylinder head between intake and exhaust valve as shown on the left hand side in Figure 3. In-cylinder pressures were recorded for 100 consecutive cycles at every one degree CA by a Labview ${ }^{\mathrm{TM}}$ software PC-based acquisition system. Ensemble average values were represented for thermodynamic engine results. One zone of first law thermodynamics model [21] without heat transfer was use to calculate heat release rate and mass fraction burnt.

\section{IMAGE AQUSITION SYSTEM}

A NAC Memrecam fx 6000 high speed video camera coupled with a DRS Hadland Model ILS3-11 intensifier is the major system used to record the high speed chemiluminescence images.Total chemiluminescence was recorded through a UV-Nikkor $105 \mathrm{~mm} \mathrm{f/4.5} \mathrm{lens.} \mathrm{The} \mathrm{intensifier} \mathrm{was} \mathrm{set} \mathrm{at} 60 \%$ gain. The camera was triggered at the same time as the data acquisition system to simultaneously record images and in- cylinder pressure data. The camera recorded images at a speed of 10,000 frame/sec with a resolution of $512 \times 248$ pixels. Therefore, time-resolved images of less than one degree crank angle per image at an engine speed of 1600 rpm, were acquired. 
An image showing the geometry of the cylinder head with valves, injector and spark plug positions is shown in Figure 3. Fifteen consecutive cycles were recorded for each test condition. From these cycles, one representative image for each point of interest was subjectively selected and the image enhanced by means of a MATLAB-based image processing routine. An average intensity and light area was calculated at each crank angle and presented together with the heat release rate and mass fraction burnt plots. Light area represents the ratio of the pixel which shows combustion and total pixels of combustion chamber.

$$
\text { Light Area }=\frac{\text { Pixel of Combustion }}{\text { Total Pixelof Chamber }} \times 100
$$

Additionally, probability images from the raw data of all 15 cycles were produced. Each pixel of probability image intensity was calculated by the number of cycles in which intensity exceeds the threshold value.

$$
\text { Pixel of Probability Image Intensity }=\frac{N}{15} \times 100
$$

Where $\mathrm{N}=$ number of cycles in which intensity exceed the combustion threshold values.

Then, value in each pixel was converted to black and white probability image. Where pixels are black, chemiluminescence emission occurred repeatedly in this area and vice versa for white pixels. The probability images are displayed under the selected representative images for the same crank angle.

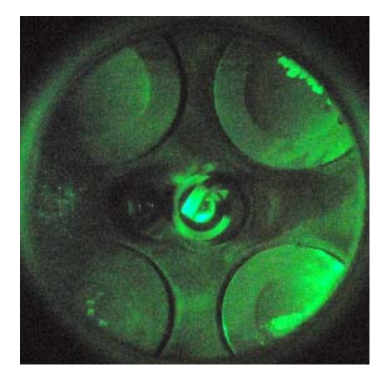

Figure 3. Geometry of cylinder head

\section{RESULTS AND DISCUSSION}

\section{PRELIMINARY RESULTS}

To investigate the effect of blended and pure alcohol fuels, preliminary investigations with only pressure data acquisition were carried out before imaging. Figure 4(a) shows the measured pressure traces with spark ignition and Figure 4 (b) the pressure traces without spark. When the maximum percentage of blended alcohols are less than or equal to 50 percent, peak cylinder pressures become higher and combustion phasing becomes more advanced than that of pure gasoline as alcohol percentage is increased. Methanol blended fuels in the range of 0 -50 percent yield the highest cylinder pressures and most advanced combustion while pure gasoline results in the lowest cylinder pressure and slowest burning combustion, hence higher in-cylinder pressure during the expansion stroke seen in the graph. The methanol results are consistent with those reported in previous studies [9, 10]. However, Li et al. [10] found that ethanol fuel resulted in retarded and slower combustion than gasoline. This is likely caused by the different injection timing used. When fuel injection took place in the compression stroke in [10], the fuel stratification was more pronounced and the greater charge cooling effect of ethanol Page 6 of 19 
would lower the charge temperature resulting delayed autoigntion. In the current study, fuel was injected into hot burned gas before the induction process and would have fully evaporised when it was mixed with air.

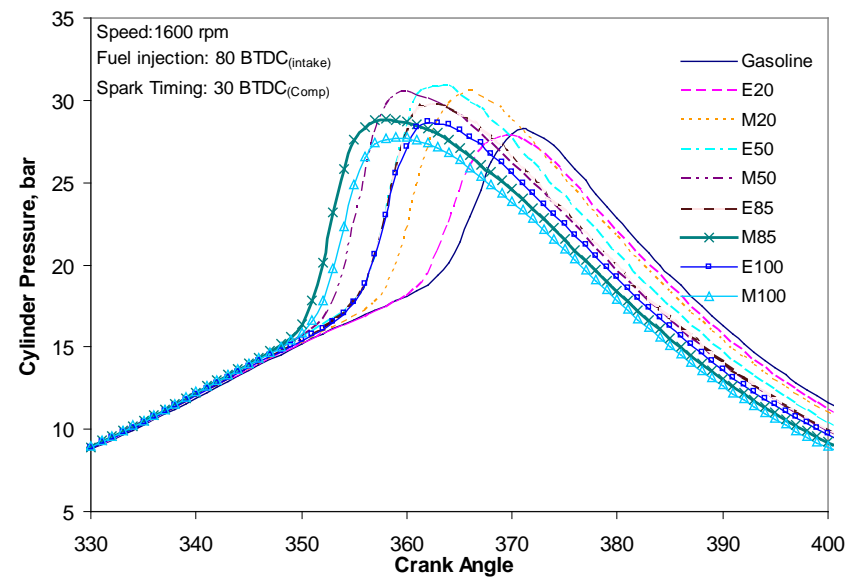

(a) Spark-assisted ignition

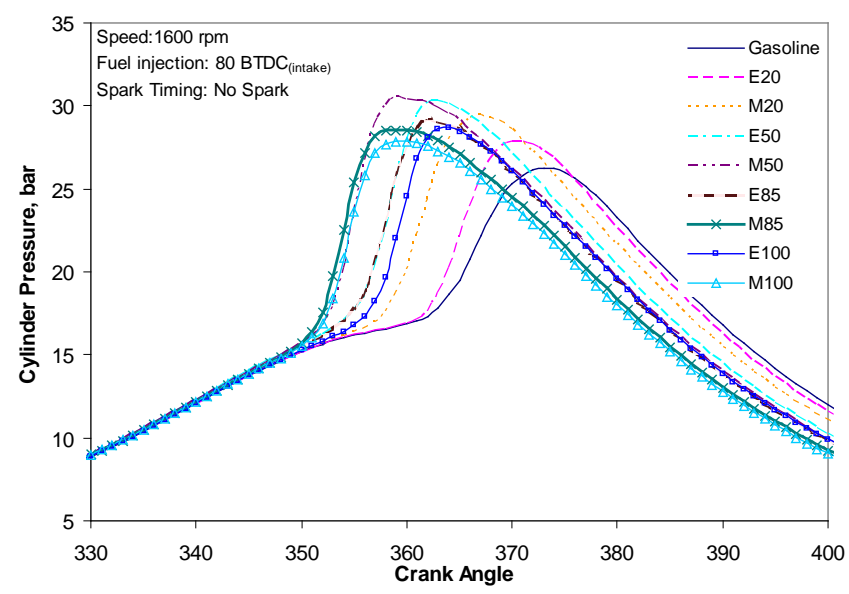

(b) Non- Spark-assisted ignition

Figure 4. Cylinder pressure for all fuels at stoichiometric mixture

For the implementation of CAI combustion through negative valve overlap, the most important factor affecting the combustion is the amount and temperature of trapped residual gas. Figure 5 presents the amount of hot residual gas trapped via the negative valve overlap for all nine fuels tested. The trapped residual amount was calculated by the ideal gas law.

$$
m_{r}=\frac{P V}{R T}
$$


Where

$$
\begin{aligned}
& \mathrm{P}=\text { In-cylinder pressure at EVC } \\
& \mathrm{T}=\text { Burnt gas temperature at EVC }
\end{aligned}
$$

The burnt gas temperature was assumed to be equal to the temperature measured by a thermocouple located in the exhaust port. Due to the lower exhaust gas temperatures of oxygenated fuels, a higher amount of residual gas from the previous cycle was trapped in the cylinder when employing alcohol blended fuels, in particular methanol. The effect of increased hot residual gas mass when using alcohol-blended fuels increases the compression charge mixture temperature above that of pure gasoline, as shown in Figure 6. As a result, it may have lead to the earlier autoignition of alcohol fuels.

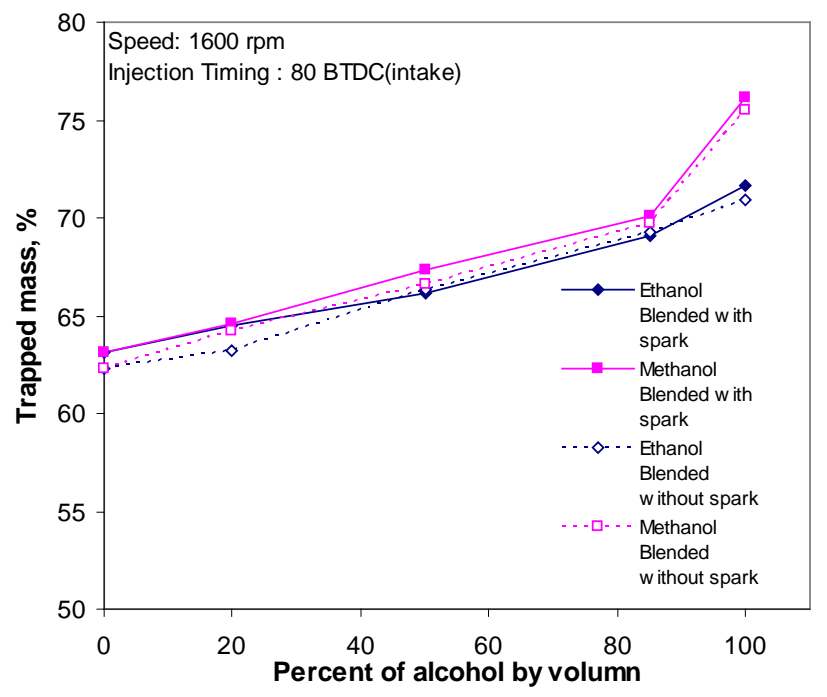

Figure 5. Trapped residual gas for all fuels

Due to their higher RON/MON number, alcohol fuels should behave as higher resistance to autoignition than that of gasoline. However, the results from the current and previous study [8, 9] shown that alcohol fuels are more ignitable under high residual/high temperature condition. They have shown better tolerance to EGR at low load [7]. Therefore RON/MON are sometimes not a good indication of autoignition resistance under high residual conditions in CAI combustion as the previous study noted [7, 22]. In addition, the greater amount of alcohol fuels required for stoichiometric combustion leads to higher in-cylinder pressure seen during the negative valve overlap period shown in Figure 7. However, the heat release rate results in Figure 7 seem to be contrary to the expectation that methanol should produce the largest charge cooling effect and hence the highest negative heat release rate. Instead the gasoline fuel seemed produced more charge cooling effect. Such results, however, could indicate more heat release actions may have taken place with alcohol fuels. In order to verify if this was the case, chemical kinetic modeling and in-cylinder sampling should be employed for further studies. 


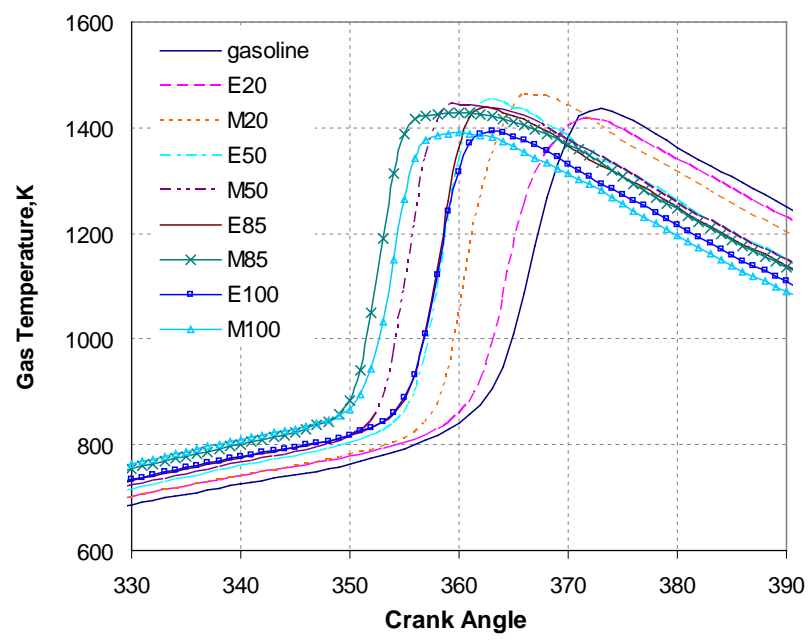

(a) Spark -assisted ignition

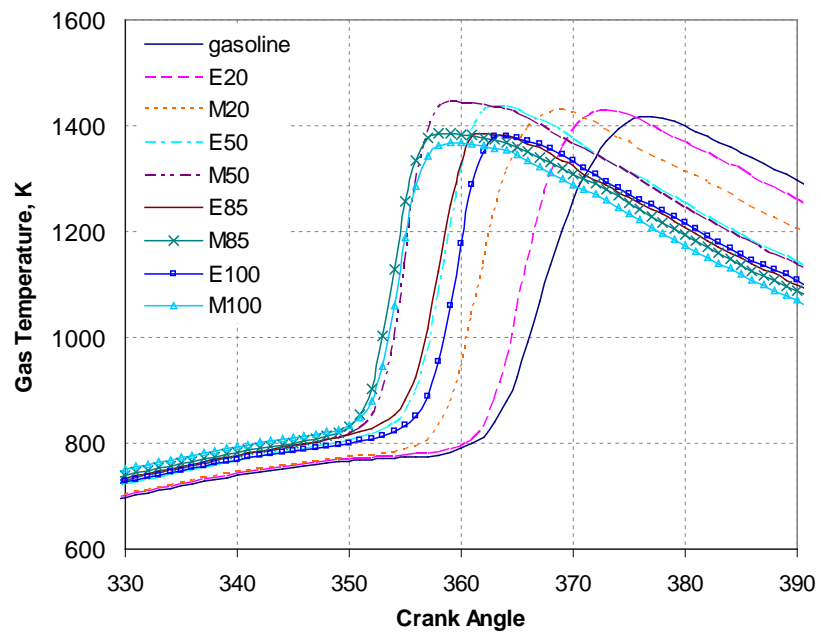

(b) Non- Spark-assisted ignition

Figure 6. In-Cylinder gas Temperature for all fuels, spark timing of 30 CA BTDC.

Page 9 of 19 

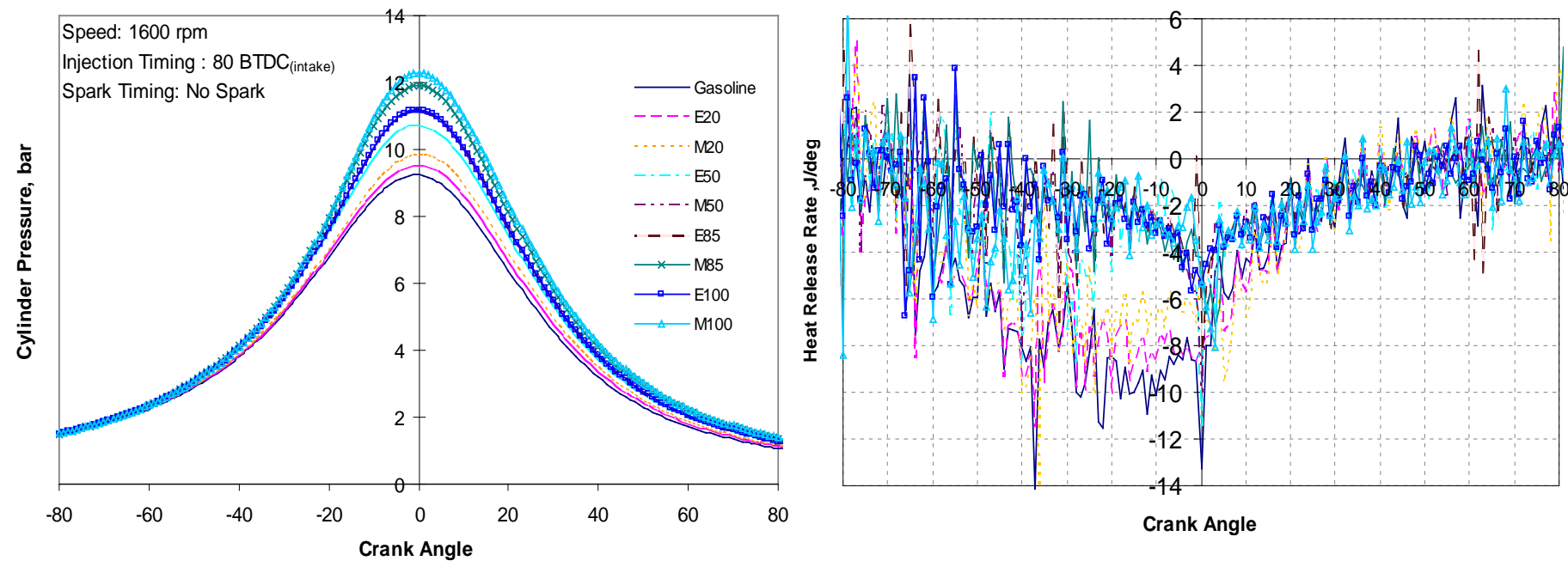

Figure 7. In-cylinder pressure and heat release rate at re-compression stroke

In terms of heat release rate, Figure 8, oxygenated fuels exhibit higher values and advanced combustion phasing than that of gasoline. Higher compression temperatures and simultaneous combustion initiation sites are responsible for these features. As Figure 7 shows, the higher charge temperature of alcohol fuels are caused by more heat release reactions of such fuels during the negative valve overlap period. As Figure 8a shows, there are significant delays between the spark timing at 30 CA BTDC and first noticeable heat release. The M85, M100, and M50 have the shortest ignition delay, followed by E100, E85, and E50 of identical delays, then M20 and E20, with gasoline fuel having the longest ignition delay. Comparison of spark-assisted heat release in Figure 8a and pure CAI combustion results in Figure 8b show that the presence of spark has a marginal effect in advancing the combustion process of alcohol fuels but a significant effect on gasoline.

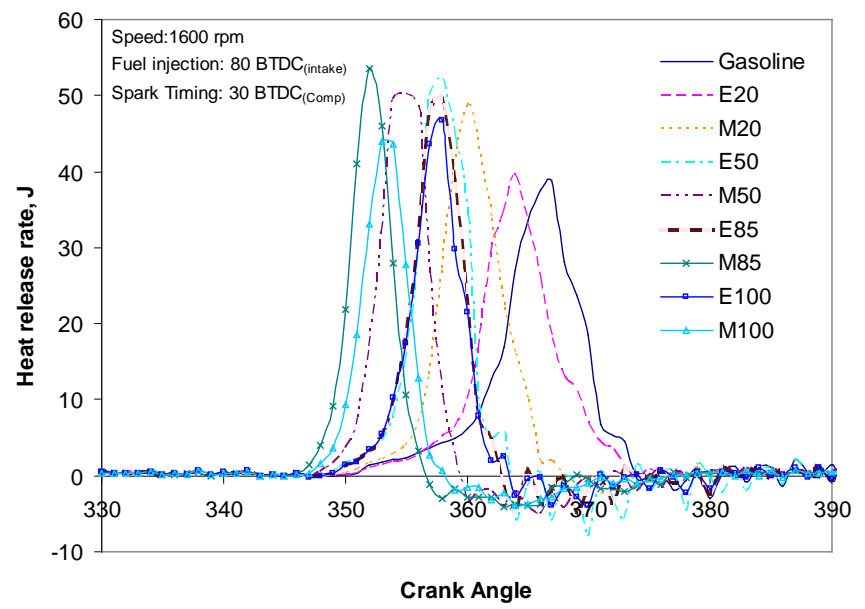

(a) Spark-assisted ignition

Page 10 of 19 


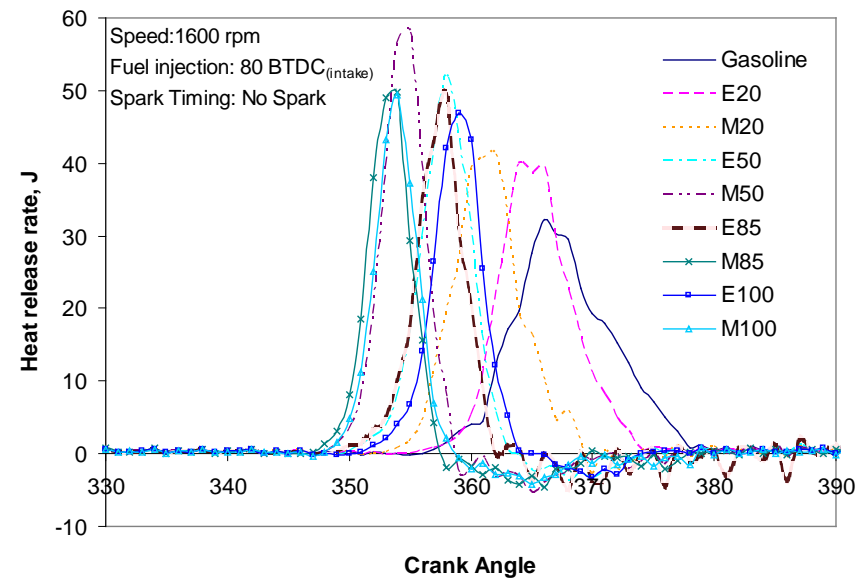

(b) Non- Spark-assisted ignition

Figure 8. Heat Release Rate for all fuels

\section{TOTAL CHEMILUMINESCENCE IMAGES}

\section{Spark-assisted ignition}

\section{- Gasoline}

Figure 9 shows the total chemiluminescence images and combustion characteristics of gasoline with sparkassisted ignition. The images at the top left hand side show the combustion emissions during the negative valve overlap period. There is combustion clearly occurring on these shots. During this re-compression process the charge temperature increases, further exacerbated by the hot residual gas present. Consequently, high temperature fuel reforming reactions take place after the injection of fuel and air mixture from the air-assisted injector as shown by previous modeling study of Cao et al [5]. However, such reactions do not produce sufficient heat to be detected from the in-cylinder pressure and subsequent heat release analysis.

With spark initiation at 330 degree CA, the first visible image is seen around the centre of the combustion chamber at about 340 degree CA With propagation from the centre, the flame occupies the whole combustion chamber by 360 degree CA. The heat release rate and mass fraction burnt curves exhibit insignificant values but the area and intensity of the combustion images increase steadily. At the same time of flame travelling, autoignition takes place on some local area which attains self -ignition temperature enhanced by expanding flame front and rising piston. Autoignition area near the wall can be seen on the top left hand side in the forth image in Figure 9. Flame propagation lasts for $20 \mathrm{crank}$ angles, before it is overtaken by the sudden heat release from independent autoignition sites as shown by the 100\% image intensity in Figure 9. During this period, the intensity of the image increases until reaching the maximum at 365 degree CA while the heat release rate starts to increase suddenly and reaches its maximum value at the same crank angle. Another significant feature visible is soot formation occurring from 355 degree CA indicated by the brighter spots in the images. The flame originated from the spark discharge agrees well with Persson et al [16] but was opposite to the results of Aleiferis et al [18] in which the reacting structures were appeared near to the wall as pure CAI combustion. This could be caused by the low luminescence of lean-burn combustion near the spark plug in [18], which was not detected by the camera due to its low sensitivity.

Page 11 of 19 
Except for the crank angle with the maximum value, the timing of image intensity does not correspond with the heat release rate curves, such as the start of combustion and combustion duration. The timing of mass fraction burnt is delayed from percentage of light area. The delay between the visible flame and detectable heat release rate has been observed for normal spark ignition combustion. However, the time delay seen in the current study is much greater and it is caused by the slower heat release reactions in the presence of large residual gases. There are two possible reasons for the discrepancy between HRR and image. (i) The leakage from the piston ring in the optical engine is higher than production engine which can reduce the pressure rise and hence loss heat release resisted by pressure measurement .(ii) It is known that chemiluminescence is a more sensitive technique to detect the combustion reactions which may not generate sufficient heat release.

The probability images illustrated in the bottom row show that most of the first visible signal commences at the centre of the chamber, this is because of spark domination. Flame propagation plays the major role in combustion during the earlier period. Beyond 350 degree CA however, some independent sites attain local spontaneous autoignition and the heat release rate experiences a sudden rise. At TDC, the combustion is dominated by the multiple autoignition heat release as shown by both the images and the heat release rate curve.

\section{- Ethanol}

The total chemiluminescence images of ethanol with spark discharge are shown in Figure 10. In contrast to gasoline, there is no chemiluminescence emission captured during the re-compression. However, the heat release curves and pressure cures in Figure 7 suggest that some heat release reactions have taken place but such reactions do not generate much chemiluminescence.

Due to the spark-assisted ignition, the first visible flame occurs at the centre of the combustion chamber and at nearly the same time as with gasoline at 340 degree CA. At 344 degree CA, another independent combustion site has appeared. Combustion rapidly spreads over the whole combustion chamber taking only 6-10 degree crank angle, whereas gasoline combustion takes 20 degree CA. The corresponding image illustrates this with self-ignition of the mixture occurring at the bottom right hand side at 344 degree CA. Later, combustion luminosity still remains visible over the entire chamber for 15 degree CA. The images correspond well with higher and earlier of heat release rate of faster combustion shown in the heat release curve. There are two reasons responsible for this faster burning combustion. Firstly, the higher flame speed properties of ethanol as shown in Table 2. Secondly, multiple regions attain self-ignition earlier and more readily than gasoline as a result of higher compression temperatures as explained by Figure 6a.

Like gasoline combustion, there is a long delay between the chemiluminescence emission and heat release rate. However, the time lag of ethanol combustion is shorter. The role of flame propagation for ethanol combustion diminishes at an earlier crank angle. Hence, simultaneous self ignition at multiple sites reduces the time delay between the rise of in-cylinder pressure and chemiluminescence signal.

Represented by the very dark areas, the probability images show the influence of spark-assisted ignition which initiates combustion at the centre of chamber. Like gasoline combustion, flame propagation dominates the process during the early period. Shortly afterwards, autoignition consumes the remaining charge mixture resulting in the entire chamber contents combusting. Moreover, for most of the cycles, combustion terminates around 370 degree CA which is sooner than that of gasoline. However, ethanol displays more cycle to cycle variation of autoignition timing than gasoline, illustrated by the brighter pixel area of the probability images.

Page 12 of 19 


\section{- Methanol}

Figure 11 presents the total chemiluminescence images of methanol with spark-assisted ignition. Similar to ethanol, which has only single - stage ignition, no chemiluminescence was visible during the re-compression stroke even though the gas charge had the highest temperature of all three fuels, as shown in Figure 6a.

Although at a relatively weak intensity, methanol combustion originates near the centre of the combustion chamber at the same CA as gasoline and ethanol, of 340 degree CA. Subsequently, the flame rapidly spreads out from the centre to the outermost area, populating the whole chamber within 6-7 degree CA and prevailing for less than 10 degree CA. Meanwhile, many independent sites around the perimeter of the combustion chamber attain spontaneous autoignition shortly after the start of flame propagation as shown by image at 346 degree CA. Because of its highest laminar flame speed and earlier simultaneous autoignition, methanol results in the shortest combustion duration of only 15-20 degree CA accompanied by the rapid increase in the light area shown in Figure 11.

Like the gasoline and ethanol fuels, the intensity and percent of light area appear earlier than the heat release rate and mass fraction burnt measured from the in-cylinder pressure. However, the time delay is of a very short period. As already discussed, spontaneous self ignition dominates shortly after spark-assisted ignition begins, reducing time lag between images and heat release rate. Of significant note, the maximum image intensity of methanol is very low compared to both gasoline and ethanol fuels.

The dark area of the probability image shows the influence of the spark discharge in initiating combustion at the center of the chamber. However, the effect of this spark assistance is overcome by autoignition at an early crank angle. Hence autoignition plays a more significant role than flame propagation in the combustion process when using methanol as a fuel. Also, the probability images verify the rapid combustion of methanol which, for most of the imaged cycles, terminates combustion before 360 degree CA. Crank angle of autoignition exhibits significant distribution in term of brighter full plane images.

\section{$\underline{\text { Non-Spark- assisted ignition }}$}

\section{- Gasoline}

Figure 12 shows total chemiluminescence images and characteristics of gasoline combustion without sparkassisted ignition. Similar to spark-assisted combustion, during the re-compression stroke the images show luminous features of fuel reforming reactions of branched hydrocarbon molecules in gasoline.

Because of the absence of a spark discharge to ignite the charge mixture containing hot residual gas, autoignition temperature is attained solely by compression and heating from the hot residual gas. Thus, the first visible image was captured around 356 degree CA, notably later than combustion with spark-assisted ignition. Interestingly, the combustion was initiated near the perimeter of the combustion chamber rather than near the centre, as with spark-assisted ignition. Autoignition is achieved at multiple sites simultaneously near the cylinder wall and not throughout the entire combustion chamber. Afterwards, as a consequence of first ignited combustion sites, the temperature of other areas is increased sufficiently to achieve self-ignition. It is not possible for flame propagation to be responsible for this combustion because only 5 degree crank angles were required for the flame to engulf the whole chamber whereas flame propagation-based spark-assisted combustion took almost 20 degree crank angle to have progressed to a similar extent. The combustion emission then persists

Page 13 of 19 
in the whole chamber for the next 15 degree crank angle, terminating around 380 degree CA, the same crank angle as for combustion with spark-assisted ignition. These results are similar to the results of Persson et al [16] in which the flame was initiated around the outer rim of image area. However, the slower speed of flame occupied the entire chamber presented in the previous paper [16]. The reforming reaction as shown in the recompression stroke possibly enhanced the CAI combustion in the current study.

The probability images exhibit dark areas around the periphery of the chamber at the beginning of combustion. This indicates that the most susceptible positions for autoignition are located around the perimeter of combustion chamber; this corresponds with the findings of Persson et al [16] and Aleiferis et al [18] in which the CAI/HCCI was achieved with the aiding of internal exhaust gas recirculation. It was postulated that the mixing with trapped hot gas created the spatial hot sources like spark discharge distributed in the combustion chamber. In the current study, those hottest gases were possible affected by dynamic flow to distribute around the perimeter of chamber. However, there is no clear evidence of this occurring in this study. In-cylinder temperature measurements will be required to elucidate the cause and will be carried out by a PLIF technique in the future. However, another plausible explanation for the first autoignition sites near the cooler cylinder wall is the so-called negative temperature coefficient phenomenon at intermediate temperature range during which the low temperature autoignition reactions slow down at elevated temperatures. Due to the lack of spark discharge to assist ignition at any specific crank angle, the commencing of autoignition varies significantly.

\section{- Ethanol}

The total chemiluminescence images of ethanol without spark-assisted ignition are shown in Figure 13. Without initiation from the spark discharge, oxidation commences late at a crank angle of around 351 degree CA. Ethanol combustion takes place earlier than gasoline but proceeds with the same process. The combustion initiation sites are located near the perimeter of the chamber as that of gasoline. In addition, the images show that ethanol achieves simultaneously autoignition covering nearly the whole combustion area, the initial oxidations increasing the charge temperature and aiding the remaining fresh mixture to complete autoignition. Subsequently, the combustion persists for 15 degree crank angle and then terminates at 370 degree CA, almost the same time as spark-assisted ignition combustion. Without the spark discharge, it can be said that simultaneous autoignition of multiple regions over the entire chamber plays an important role in consuming the charge mixture within a shorter period of time. Combustion of ethanol occurs faster and starts earlier than that of gasoline. The higher gas temperatures at the beginning of the compression stroke with ethanol have an effect on the early combustion timing while simultaneous autoignition of many independent sites are responsible for the faster combustion.

The Intensity and percent of light area curves show the same result but have a slight time lag with heat release rate and mass fraction burnt, when compared with spark-assisted combustion. The probability images show cycle to cycle variation of the crank angle at which autoignition occurs. The images also show that autoignition occasionally starts before 351 degree CA. Autoignition attains at specific sites around the perimeter of the combustion chamber.

\section{- Methanol}

Figure 14 illustrates the total chemiluminescence images of methanol without spark assistance. There is no chemiluminescence detected during the re-compression stroke.

Interestingly, total chemiluminescence of methanol is similar between with/without spark-assisted ignition. Figure 14 shows that the autoignition is achieved at 341 degree CA, nearly the same time as that from spark Page 14 of 19 
discharge at 340 degree CA, as shown in Figure 11. Of significant difference compared to spark-assisted combustion, the autoignition sites appear around the perimeter of the chamber. The crank angle in which charge temperature attain autoignition is almost the same with spark igniting combustion. Therefore, it is possible that some cycles of spark-assisted combustion were initiated by autoignition while some cycles are dominated by spark ignition. Moreover, the image intensity and percent of light area plots look similar to those of non- sparkassisted combustion and have a time lag with heat release rate and mass fraction burnt.

The probability images show the likely areas of autoignition are located on the periphery of the combustion chamber biased towards the exhaust valves, the same side to that of gasoline, where the charge is exposed to higher surface temperature. For most cycles, the bulk charge was consumed in less than 10 degree CA and combustion terminated before 355 degree CA. Compared with the previous fuels, CAI combustion with methanol as the fuel is the fastest and earliest initiating process.

\section{CONCLUSIONS}

In this paper, in-cylinder pressure and chemiluminescence results of CAI combustion of methanol, ethanol, gasoline and their mixtures are presented and analysed. The heat release rate and the mass fraction burned data from the in-cylinder pressure measurements are compared with the high speed chemiluminescence images taken by an intensified high speed colour video camera. As a result, the effect of fuel properties and spark discharge on the combustion characteristics has been identified and the main conclusions can be summerised as follows:

- During the re-compression stroke, the heat release curves indicate more heat being released from directly injected alcohol fuels. However, no chemiluminescence was detected for alcohol fuels. In comparison, gasoline fuel exhibited luminous emission but little heat release was registered by the heat release analysis. In-cylinder sampling and chemical kinetic analysis can be used to verify the presence and nature of the chemical reactions during the negative valve overlap period.

- The effect of spark discharge is prominent shown in the gasoline fuel but not much effect in alcohol fuels. This is because the CAI combustion of alcohol fuels started earlier due to increased charge temperature.

- With certain mixture composition and temperature spark discharge can advance the start of heat release process and normally results in the location of ignition at the center of chamber.

- With spark-assisted ignition, flame propagation dominates the combustion at the early period followed by spontaneous autoignition for CAI combustion. Because of the high dilution rate, the flame propagates at a slow speed and accounts for a very small portion of the total heat released.

- When using oxygenated fuel, flame propagation was diminished sooner due to earlier simultaneous self ignition of charge mixture.

- Methanol shows fastest and earliest autoignition combustion, followed by ethanol while gasoline is the slowest and latest combustion. Charge temperature during compression is the key factor for this kind of engine.

- Chemiluminescence images show that perimeter area of the chamber is the preferred sites for autoignition.

- Due to limited molecule and reaction pathway, oxygenated fuels, particularly methanol, present lower image intensity for all of the emissions compared with gasoline.

\section{REFERENCES}

1. Hua Zhao (2007), "HCCI and CAI engines for the automotive industry”. CRC Press LLC, ISBN 978-14200-4459-1, Woodhead Publishing Lt., ISBN 978-1-84569-128-8. 
2. Leach, B., Zhao, H., Li, Y., and Ma, T. (2005), “Control of CAI Combustion through Injection Timing in a GDI Engine with an Air-Assisted Injector” SAE Paper No. 2005-01-0134.

3. Yufeng, L., Zhao, H., Nikolaos, B., Ma, T. and Leach, B.(2006), "Effect of Injection timing on Mixture and CAI Combustion in a GDI Engine with an Air-Assisted Injector” SAE Paper No. 2006-01-0206

4. Yufeng, L., Zhao, H., Nikolaos, B., and Ma, T. (2007), "Parametric Study on CAI Combustion in a GDI Engine with an Air-Assisted Injector" SAE Paper No. 2007-01-0196.

5. Li Cao, Hua Zhao and Xi Jiang, (2007), “Investigation into Controlled Auto-Ignition Combustion in a GDI Engine with Single and Split Fuel Injections” SAE Paper No. 2007-01-0211.

6. M. Christensen, B. Johansson and P. Einewall, (1997), “ Homogeneous Charge Compression Ignition ( HCCI) Using Isooctane, Ethanol and Natural Gas - A Comparison with Spark Ignition Operation” SAE Paper No. 972874

7. Aaron Oakley, Hua Zhao, Nicos Ladommatos and Tom Ma (2001), "Dilution Effects on the Controlled Auto-Ignition(CAI) Combustion of Hydrocarbon and Alcohol Fuels”, SAE Paper No. 2001-01-3606

8. Norimasa Iida, (1994), "Combustion Analysis of Methanol-Fueled Active Thermo-Atmosphere Combustion (ATAC) Engine Using a Spectroscopic Observation” SAE Paper No. 940684.

9. Hui Xie, Zhipeng Wei, Bangquan He and Hua Zhao (2006), “Comparison of HCCI Combustion Respectively Fueled with Gasoline, Ethanol and Methanol through the Trapped Residual Gas Strategy”, SAE Paper No. 2006-01-0635

10. Yufeng Li, Hua Zhao, and Nikolaos Brouzos (2008), "CAI Combustion with Methanol and Ethanol in a Air-Assisted Direct Injection Engine”. SAE Paper No.2008-01-1673.

11. John E. Dec and Christoph Espey,(1998), “Chemuluminescence Imaging of Autoignition in a DI Diesel Engine' 'SAE Paper No. 982685.

12. E. Mancaruso, S.S. Merola and B. M. Vaglieco, (2008), "Extinction and Chemiluminescence Measurements of HCCI Mode in Diesel Engine Operation with Late Injection’’ SAE Paper No. 2008-01-0027.

13. H.Zhao, Z.Peng and T.Ma (2004), "Investigation of the HCCI/CAI Combustion Process by 2-D PLIF Imaging of Formaldehyde’’. SAE Paper No. 2004-01-1901.

14. R.Collin, J.Nygren,M.Richter and M.Alden (2003), "Simultaneous OH-and Formaldehyde-LIF Measurements in an HCCI Engine’'. SAE Paper No. 2003-01-3218.

15. N.Graf, J. Gronki, and C. Schulz (2001), "In-Cylinder Combustion Visualization in an Auto-Ignition Gasoline Engine using Fuel Tracer-and Formaldehyde-LIF Imaging’’. SAE Paper No.2001-01-1924.

16. H.Persson, A.Hultqvist and B. Johansson, (2007) "Investigation of the Early Flame Development in Spark Assisted HCCI Combustion Using High Speed Chemiluminescence Imaging’’. SAE Paper No.2007-010212.

17. J.E. Dec, W. Hwang and M. Sjoberg, (2006), “An Investigation of Thermal Stratification in HCCI Engines Using Chemiluminescence Imaging’’. SAE Paper No. 2006-01-1518.

18. P.G. Aleiferis, A.G. Charalambides, Y. Hardalupas , A.M.K.P. Taylor and Y. Urata, (2006), “ Autoignition Initiation and Development of n-heptane HCCI Combustion Assisted by inlet Air Heating, Internal EGR or Spark Discharge: An Optical Investigation’’ SAE Paper No. 2006-01-3273

19. A. Hultqvist, M. Christensen, B. Johansson, A.Franke, M.Richter and M. Alden, (1999), “A Study of the Homogeneous Charge Compression Ignition Combustion Process by Chemiluminescence Imaging', SAE Paper No.1999-01-3680.

20. Changho Yang, Hua Zhao and Thanos Megaritis, (2009), "In-Cylinder studies of CAI Combustion with Negative Valve Overlap”'. SAE Paper No.2009-01-1103.

21. Heywood, J. B., (1988) “Internal Combustion Engine Fundamentals”' McGraw-Hill, ISBN 0-07-100499-8, 1988.

22. N.Jeuland, X. Montagne and P.Duret, (2003), "Engine and Fuel Related Issues of Gasoline CAI (Controlled Auto-Ignition) Combustion ’’ SAE Paper No. 2003-01-1856.

Page 16 of 19 
Gasoline Spark Ignition (Total Chemiluminescence)
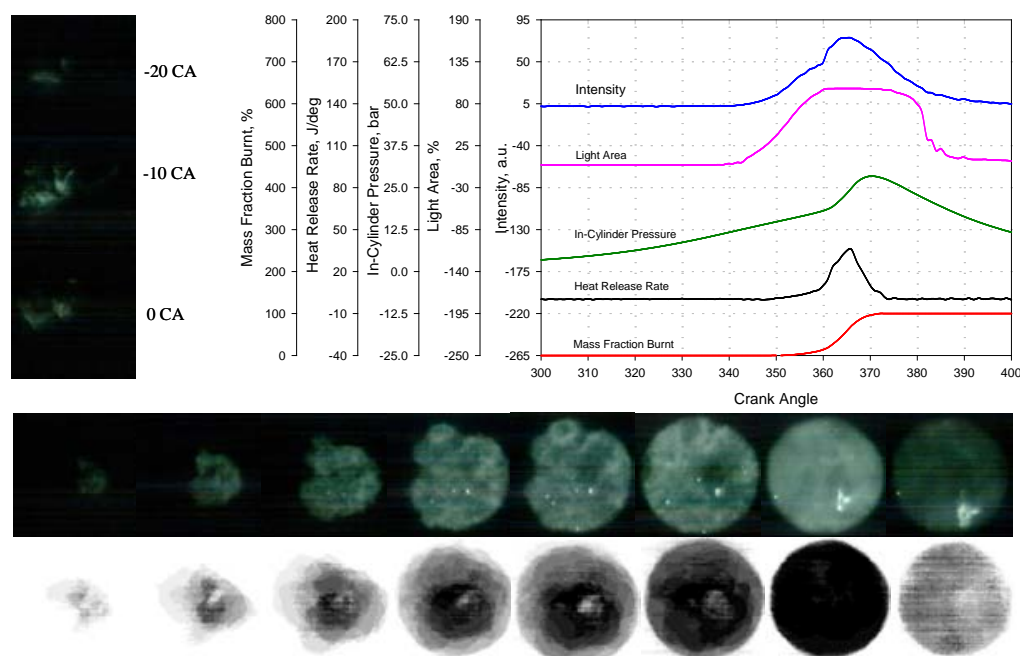

340CA

$345 \mathrm{CA}$

$350 \mathrm{CA}$

$355 \mathrm{CA}$

$357 \mathrm{CA}$
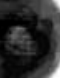

$360 \mathrm{CA}$

$380 \mathrm{CA} \quad 100 \%$

Figure 9. Total chemiluminescence image of gasoline with spark-assisted ignition Ethanol Spark Ignition (Total Chemiluminescence)
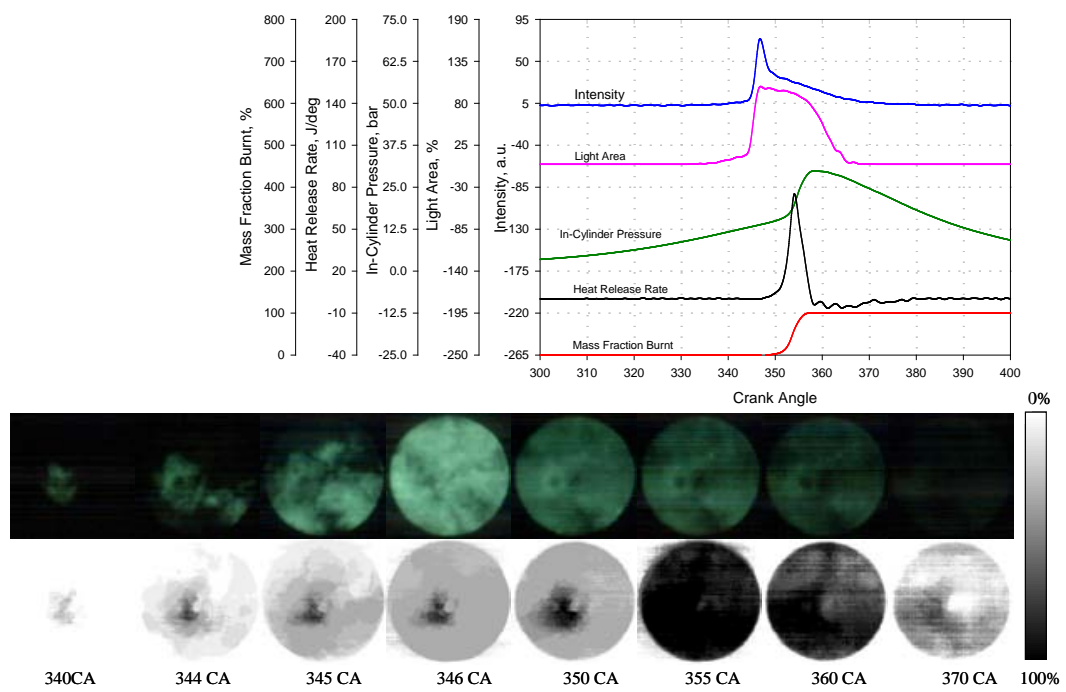

Figure 10. Total chemiluminescence image of ethanol with spark-assisted ignition 


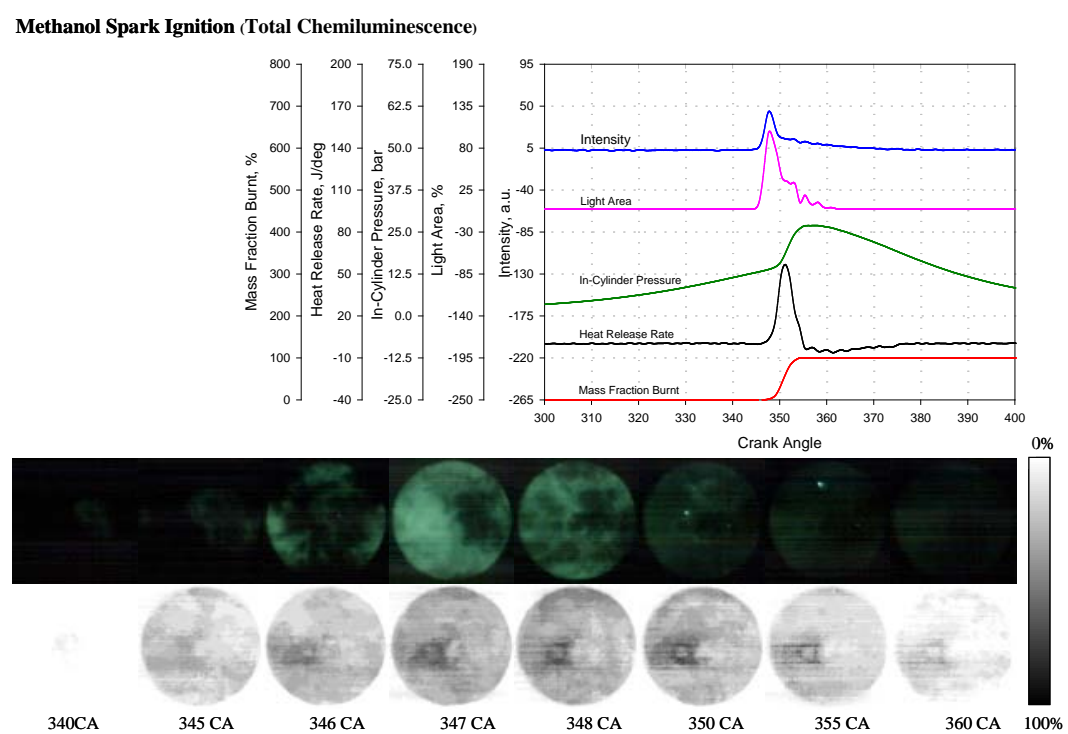

Figure 11. Total chemiluminescence image of methanol with spark-assisted ignition
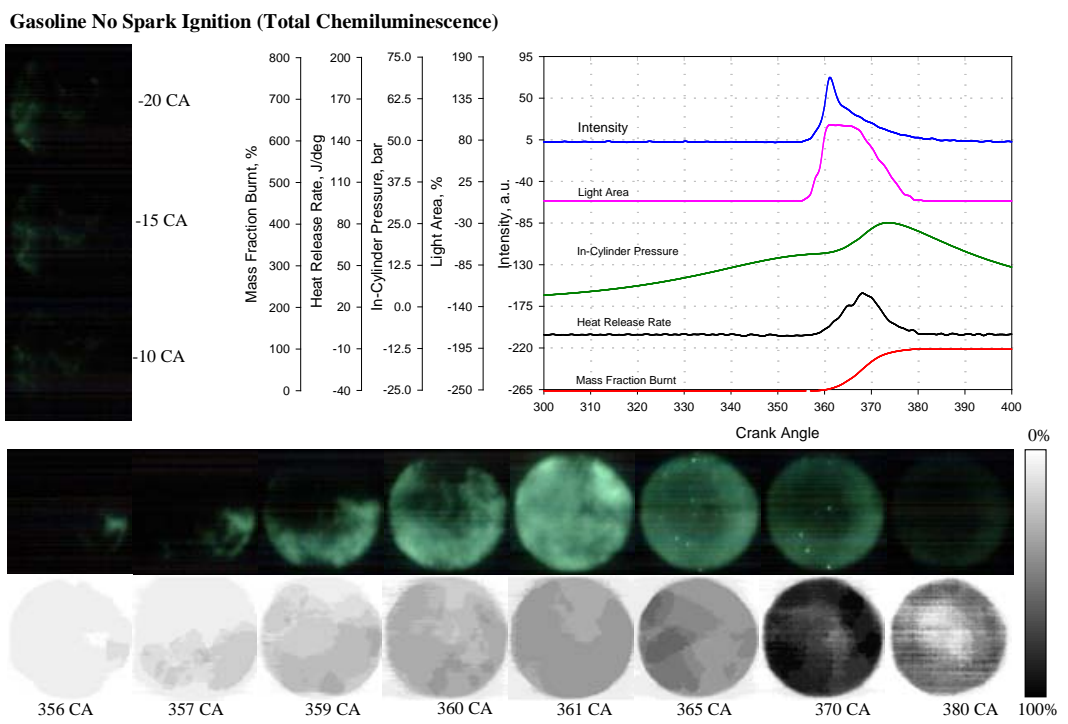

Figure 12. Total chemiluminescence image of gasoline without spark-assisted ignition 
Ethanol No Spark Ignition (Total Chemiluminescence)
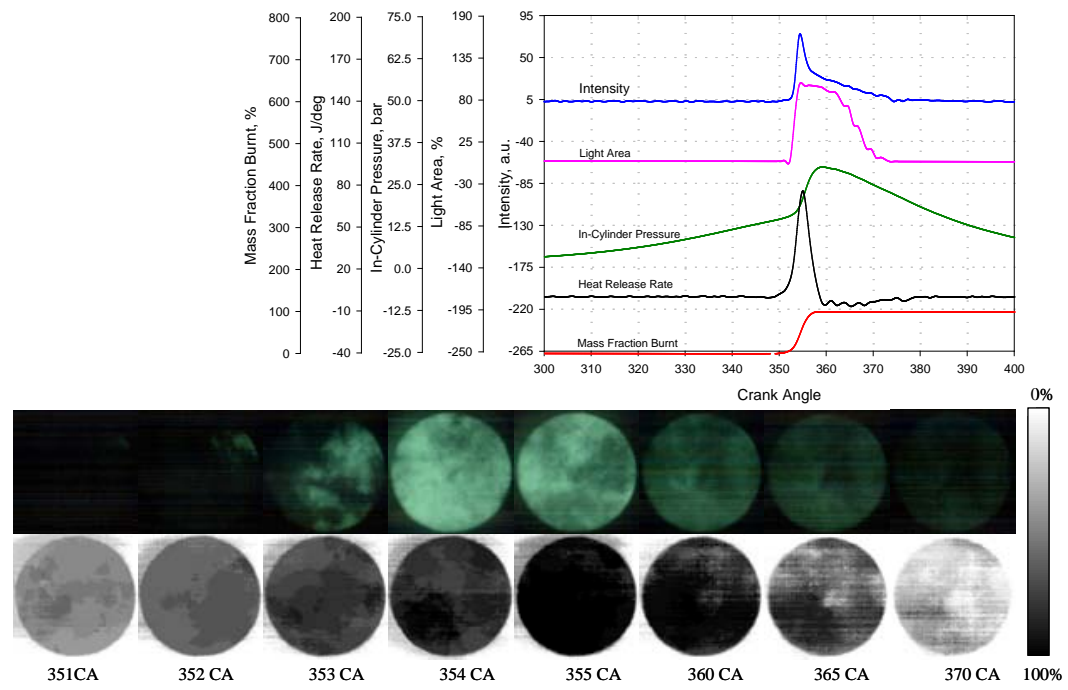

Figure 13. Total chemiluminescence image of ethanol without spark-assisted ignition Methanol No Spark Ignition (Total Chemiluminescence)
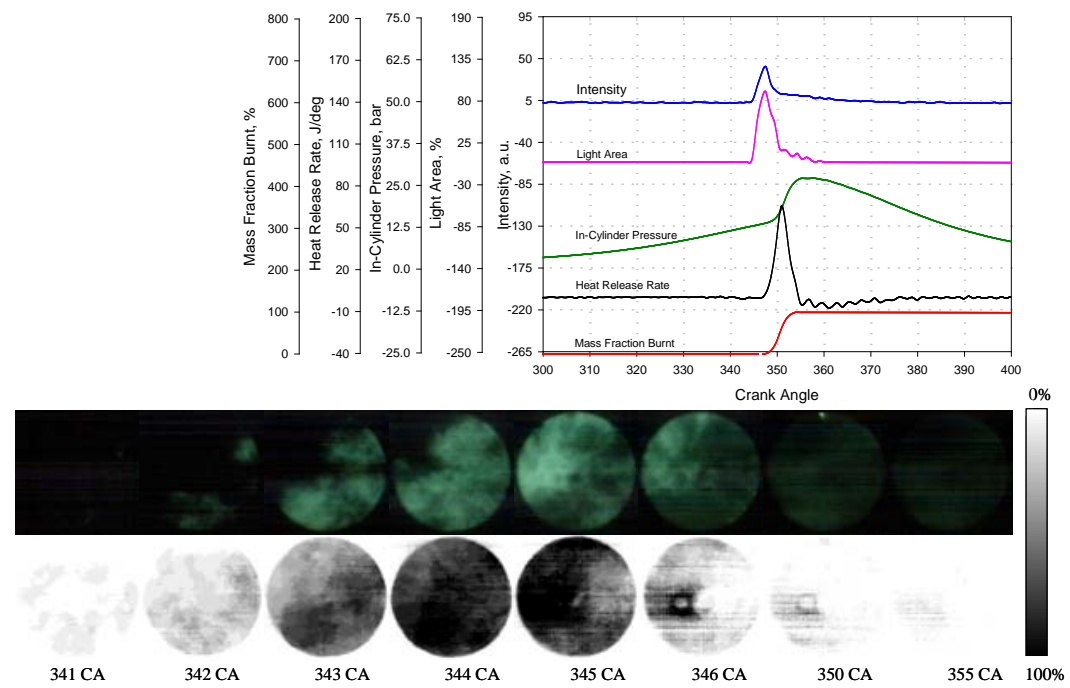

Figure 14. Total chemiluminescence image of methanol without spark-assisted ignition 